\title{
Synthesis and Electrochemical Characterization of LiVMoO $_{6}$, Obtained By Melt Quenching Method for All- Solid-State Lithium Batteries
}

\author{
Margarita Milanova ${ }^{1 *}$, Reni Iordanova ${ }^{1}$, Akitoshi Hayashi ${ }^{2}$, Masahiro Tatsumisago ${ }^{2}$ \\ ${ }^{1}$ Institute of General and Inorganic Chemistry, Bulgarian Academy of Sciences, Bulgaria \\ ${ }^{2}$ Department of Applied Chemistry, Osaka Prefecture University, Japan
}

Submission: April 24, 2017; Published: June 16, 2017

*Corresponding author: Margarita Milanova, Institute of General and Inorganic Chemistry, Bulgarian Academy of Sciences, Acad. G. Bonchev str. bld. 11, 1113 Sofia, Bulgaria, Tel: (+359) 297935 88; Fax: 359287050 24, Email: margi71@abv.bg

\begin{abstract}
Crystalline $\mathrm{LiVMoO}_{6}$ with bannerette structure was synthesized by a novel melt quenching method followed by heat treatment in order to increase the degree of crystallinity of the material. XRD, Raman and SEM investigations were performed to examine the phase formation, local structure and morphology of the obtained product. The electrochemical properties of all-solid-state-cell using $\mathrm{LiVMoO}_{6}$ as an active material were examined. Discharge-charge measurements for 10 cycles were performed in the potential range from 1.8 to $3.7 \mathrm{~V}$ under a current density of $0.1 \mathrm{~mA} \mathrm{~cm}^{-2}$ at room temperature. The assembled all-solid-state Li-In/80Li $\mathrm{S}_{2} 20 \mathrm{P}_{2} \mathrm{~S}_{5}$ glass-ceramic/LiVMoO ${ }_{6}$ battery showed poor electrochemical performance. The charge and discharge capacities began to fade immediately after the first cycle, dropping at about $83 \%$ by the $10^{\text {th }}$ discharge.

Keywords: Melt quenching technique; Cathode; All-solid-state battery
\end{abstract}

\section{Introduction}

The introduction by Sony in 1990 of the world's first commercially successful rechargeable lithium battery represented a revolution in the power source industry [1]. The performance of rechargeable Li-ion batteries depends on the properties of cathodes, anodes and electrolytes. That is why the search of newer materials, has opened a new era in the solidstate materials research. Many review papers and books have been published recent time [2-5], reveling the importance of rechargeable Li-ion batteries in the modern technology area. The main challenges of Li-ion technology are related with the enhancement of the energy efficiency and safety and to reduce the cost of their production [6]. Traditionally electrode active materials for Li-ion batteries are based on transition metals oxide compounds because of their open crystalline structures and high redox potential [3]. Among them the brannerite-type $\mathrm{LiVMoO}_{6}$ has attracted special attention both as cathode and anode material because of its open structure and interesting characteristic from a stand point of the variety of oxidation state and has been extensively studied as electrode active material in lithium batteries using conventional liquid electrolyte [7-11].
Recently we have reported for the first time data concerning the electrochemical performance of $\mathrm{LiVMoO}_{6}$ obtained by softmechanochemical syhthesis as cathode active material for the all-solid-state batteries [12]. It was found that although $\mathrm{LiVMoO}_{6}$ delivered a low specific capacity it showed a stable cycling behavior and can be further investigated as an active material for the preparation of all-solid-state batteries. Herein we present the results of synthesis, structural and electrochemical characterization of $\mathrm{LiVMoO}_{6}$, obtained by melt quenching method and its electrochemical behavior as composite positive electrode in all-solid-state batteries with $80 \mathrm{Li}_{2} \mathrm{~S} .20 \mathrm{P}_{2} \mathrm{~S}_{5}$ glass ceramic as a solid electrolyte.

\section{Materials and methods}

$\mathrm{LiVMoO}_{6}$ was obtained by melt quenching method. The sample was prepared using reagent grade $\mathrm{Li}_{2} \mathrm{CO}_{3}, \mathrm{~V}_{2} \mathrm{O}_{5}$ and $\mathrm{MoO}_{3}$. The homogenized batch of the starting compounds was melted for $20 \mathrm{~min}$ at $800{ }^{\circ} \mathrm{C}$ in alumina crucibles in air atmosphere. Crystalline material was obtained by pouring and pressing of the melt between two stainless steel plates. The quenched sample was annealed at $500{ }^{\circ} \mathrm{C}$ in air for 5 hours in order to increase 
the degree of crystallinity of the material and to improve its electrochemical performance. The phase formation was checked by XRD ( $\mathrm{CuK}_{\alpha}$, Ultima IV; Rigaku Corp.). The room temperature Raman measurement of $\mathrm{LiVMoO}_{6}$ was performed in the range $200-1200 \mathrm{~cm}^{-1}$ on a mcirco-Raman system from Jobin-Yvon Horiba (LABRAM HR-800) spectrometer with green laser (wavelength: $532 \mathrm{~nm}$ ). The morphology and microstructure of LiVMo06 were investigated by a scanning electron microscope (JEOL, JSM5300). Electrochemical performance of $\mathrm{LiVMoO}_{6}$ obtained was tested by assembling of all-solid-state cells employing $\mathrm{LiVMoO}_{6}$ as an active material. $80 \mathrm{Li}_{2} \mathrm{~S} .20 \mathrm{P}_{2} \mathrm{~S}_{5}$ (mol\%) glass-ceramic and Li-In alloy were respectively used as a solid electrolyte and a counter/reference electrode. The details of the construction of the all-solid-state test cell were described in ref [12]. The prepared all-solid-state cell was discharged and charged in the potential range from 1.8 to $0.1 \mathrm{~mA} \mathrm{~cm}^{-2}$ under a current density of $0.1 \mathrm{~mA} \mathrm{~cm}^{-2}$ at room temperature in $\mathrm{Ar}$ atmosphere using a charge-discharge measuring device (BTS-2004; Nagano). Electrochemical impedance measurements of the prepared test cells before and after discharge-charge measurements were performed using a charge-discharge measuring device (SI1260 Solartron) in the frequency range from $100 \mathrm{mHz}$ to $1 \mathrm{MHz}$.

\section{Results and Discussion}

\section{Synthesis and structural characterization of $\mathrm{LiVMoO}_{6}$ phase}

The XRD pattern of prepared $\mathrm{LiVMoO}_{6}$ is presentin Figure 1. The diffraction pattern of the obtained $\mathrm{LiVMoO}_{6}$ was indexed using "Index" software, assuming a $\mathrm{C} 2 / \mathrm{m}$ symmetry that corresponds to the monoclinic citing of the brannerite structure and shows no traces of impurity phases [13]. The diffraction peaks are intense and symmetrical evidencing the formation of a well crystallized $\mathrm{LiVMoO}_{6}$ product. Additional information about phase formation and structural features of the prepared compound was obtained by Raman spectroscopy. Raman analysis confirmed XRD results. Raman spectrum (Figure 2) of the sample displays the absorption bands typical for the various $\mathrm{MeO}_{6}$ $(\mathrm{Me}=\mathrm{V}, \mathrm{Mo}, \mathrm{Li})$ octahedral units building the lattice $[8,12,14]$. SEM images of the material at different magnifications are shown on Figure 3. As it is seen from the pictures, the prepared $\mathrm{LiVMoO}_{6}$ consists of dense agglomerates formed from irregular shaped particles in sub-micronic particles size range. Because of the high-temperature technique adopted for the synthesis of $\mathrm{LiVMoO}_{6}$, it possesses a higher degree of crystallinity but as well as a higher degree of agglomeration as compared with $\mathrm{LiVMoO}_{6}$ product obtained by soft-mechanochemical synthesis previously reported by us [12]. Its particles size and morphology is also different from the nano-scale spherical $\mathrm{LiVMoO}_{6}$ product obtained by soft-mechanochemical synthesis [12]. These results evidenced the influence of the synthesis methods on the structural and morphological features of the $\mathrm{LiVMoO}_{6}$.

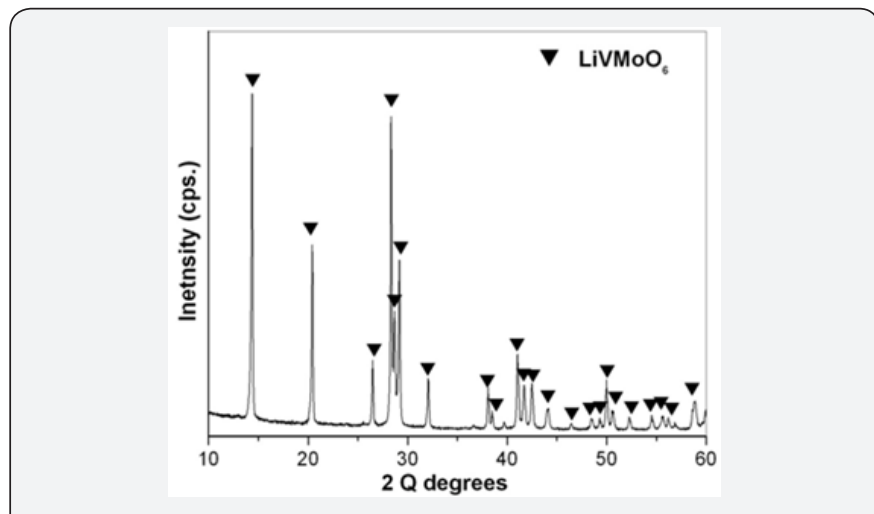

Figure 1: XRD pattern of $\mathrm{LiVMoO}_{6}$ obtained by melt quenching method.

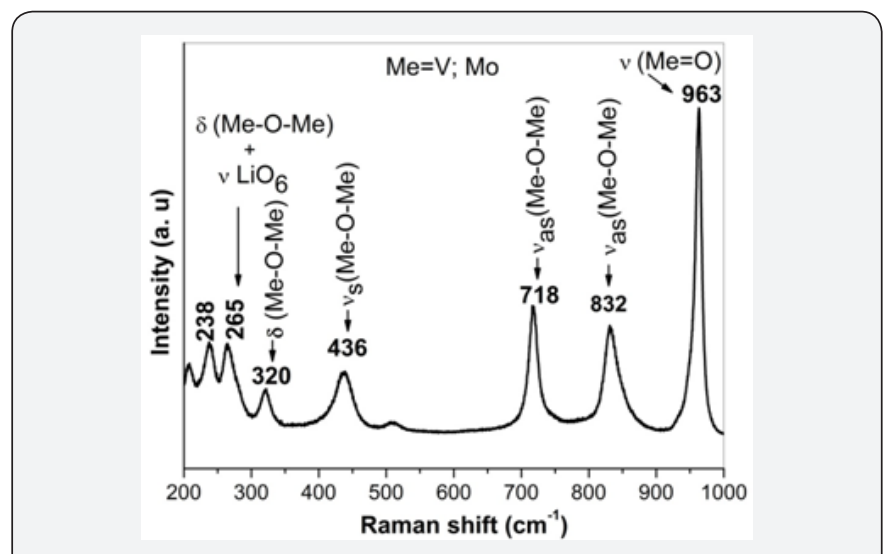

Figure 2: Raman spectrum of $\mathrm{LiVMoO}_{6}$ obtained by melt quenching method.

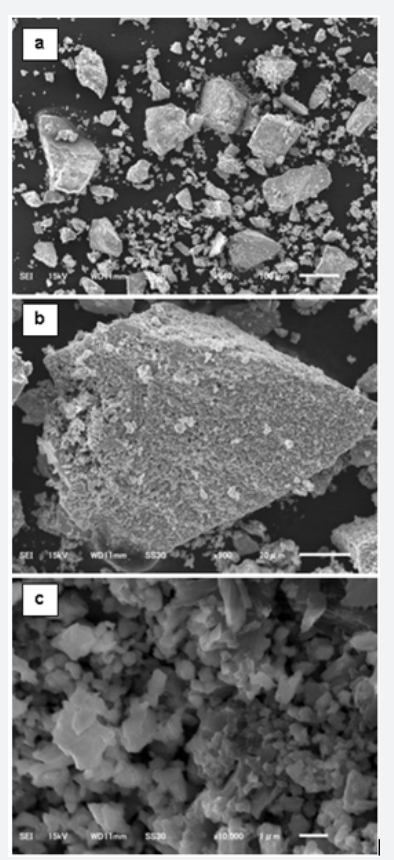

Figure 3: SEM images of $\mathrm{LiVMoO}_{6}$ obtained by melt quenching method at different magnifications, a)x140; b) x900; c) x10 000. 


\section{Electrochemical characterization}

The electrochemical properties of all solid-state-cell using LiVMoO6 as an active material were examined. The cell was initially discharged (insertion of lithium ions into $\mathrm{LiVMoO}_{6}$ active material) and subsequently charged (extraction of lithium ions from $\mathrm{LiVMoO}_{6}$ active material) between 1.8 and $3.7 \mathrm{~V}$ under a current density of $0.1 \mathrm{~mA} \mathrm{~cm}^{-2}$ at $25^{\circ} \mathrm{C}$. The discharge-charge curves of the test cell for 10 cycles are shown in Figure 4 . At the first discharge/charge cycle, the discharge capacity is about 18 $\mathrm{mAh} \mathrm{g}^{-1}$ and the charge capacity is about $50 \mathrm{mAh} \mathrm{g}^{-1}$. The charge and discharge capacities began to fade immediately after the first cycle, dropping at about $83 \%$ by the 10th discharge. The poor electrochemical performance observed can be explained by the higher degree of aggregation of $\mathrm{LiVMoO}_{6}$ particles obtained by melt quenching resulting in worse contact with the solid electrolyte. As it is known, the favorable contact at electrode/ electrolyte solid interface is key to improve electrochemical performance of all-solid-state batteries because charge-transfer reaction proceeds only at the contact interface $[15,16]$. Another possible reason may be the structural degradation of $\mathrm{LiVMoO}_{6}$ during cycling [17]. The cycling behavior of the investigated all-solid-state cell differs from the cycling behavior of the previous reported all-solid-state cell where $\mathrm{LiVMoO}_{6}$ obtained by soft mechanochemical method was employed as a composite positive electrode [12]. Although $\mathrm{LiVMoO}_{6}$ synthesized by soft mechanochemical method also delivered a low specific capacity it showed a stable cycling behavior with a sustainable reversible capacity of $35 \mathrm{mAh} \mathrm{g}^{-1}$ and a coulombic efficiency close to $100 \%$ after the second to the $10^{\text {th }}$ cycles.

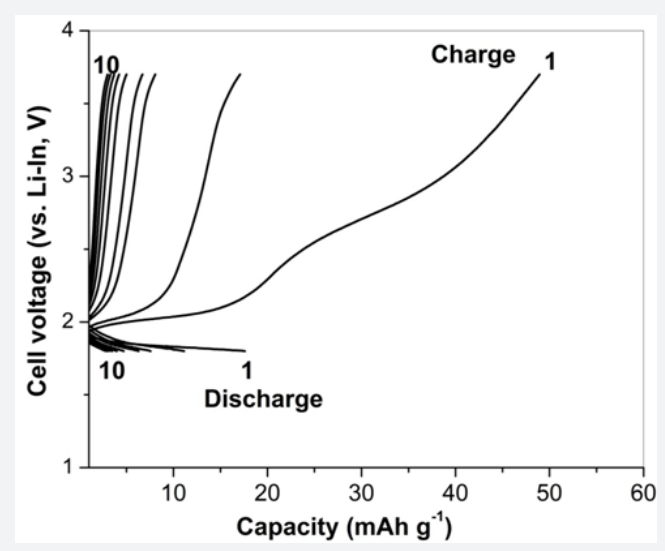

Figure 4: The charge/discharge curves of an all-solid-state LiIn/80Li 2 S. $20 \mathrm{P}_{2} \mathrm{~S}_{5}$ glass-ceramic/LiVMoO ${ }_{6}$ cell.

In order to understand the cycling behavior of the allsolid-state $\mathrm{Li}-\mathrm{In} / \mathrm{LiVMoO}_{6}$ cell, ac impedance measurements were carried out. Near capacitive response of both the fresh and cycled cells was detected characterized with incomplete semicircles with a large diameter in the shown Nyquist plots (Figure 5). Impedance results obtained also differ from the impedance results reported in reference [12], where the change in the blocking electrode behavior and an improvement of the electrochemical properties of the positive electrode upon cycling were observed.

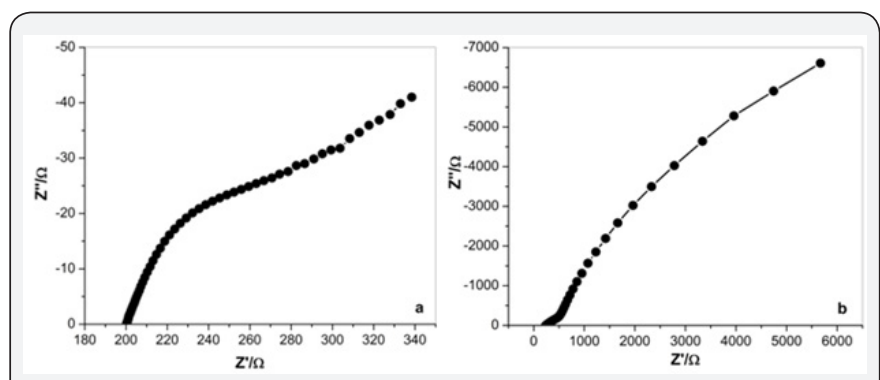

Figure 5: Nygusit plot of Li-In/80Li $\mathrm{L}_{2} .2 \mathrm{P}_{2} \mathrm{~S}_{5}$ glass-ceramic/ $\mathrm{LiVMoO}_{6}$ cell before (a) and after (b) the cycling test.

\section{Conclusion}

Single phase $\mathrm{LiVMoO}_{6}$, was successfully synthesized by applying of melt quenching method. Preparation of $\mathrm{LiVMoO}_{6}$ using high-temperature method of synthesis provides submicron-sized particles with irregular shape which are highly agglomerated. The electrochemical performance of the obtained $\mathrm{LiVMoO}_{6}$ as composite positive electrode in all-solidstate batteries was investigated. The battery shows unsatisfied electrochemical performance. A significant capacity fade occurs after 10 cycles at room temperature. It was suggested that the high degree of aggregation of $\mathrm{LiVMoO}_{6}$ particles resulting in worse contact with the solid electrolyte can be the main reason for the poor electrochemical results. The present result evidenced the importance of the synthesis method for the electrode properties.

\section{Acknowledgment}

Some of this work was done while the author M. Milanova was visiting the Department of Applied Chemistry, Graduate School of Engineering, Osaka Prefecture University under financial support by The Matsumae International Foundation (MIF) in the framework of the Matsumae International Fellowship Program April-September 2014. The same author wishes to thank all the members of Prof. Tatsumisago's group for their cooperation and support during her stay in Osaka Prefecture University.

\section{References}

1. Bruce P (1997) Solid-state chemistry of lithium power sources. Chem Commun 19: 1817-1824.

2. Minami T, Tatsumisago M, Wakihara M, Iwakura MC, Kohjiya S, et al. (2005) Solid State Ionics for Batteries. Springer-Verlag, Tokyo.

3. Jeffrey W (2010) Recent developments in cathode materials for lithium ion batteries. J Power Sources 195: 939-954.

4. Lee K T, Cho J (2011) Roles of nanosize in lithium reactive nanomaterials for lithium ion batteries. Nano Today 6: 28-41.

5. Zaghib K, Mauger A, Groult H, Goodenough JB, Julien CM (2013) Advanced Electrodes for High Power Li-ion Batteries. Materials 6(3): 1028-1049.

6. Väyrynen A, Salmien J (2012) Lithium ion battery production. J Chem Therdmodynamics 46: 80-85. 
7. Michael M, Fauzi A, Prabaharan SRS (2000) Soft-combustion (wet chemical) synthesis of a new 4-V class cathode-active material, $\mathrm{LiVMoO}_{6}$, for Li-ion batteries. Int J Inorg Mater 2: 261-267.

8. Amdouni N, Zarrouk H, Soulette F, Julien C (2003) Synthesis, structure and lithium intercalation reaction in LiVMoO6 brannerite-type materials. J Mater Sci 13: 2374-2380.

9. Liang Y, Han X, Cong C, Yi Z, Zhou L, et al. (2007) Controlled synthesis of rod-like $\mathrm{LiVMoO}_{6}$ nanocrystals for application in lithium-ion batteries. Nanotechnology 18: 135607-135613.

10. Zhou L, Liang Y, Hu L, Han X, Yi Z, et al. (2008) Much improved capacity and cycling performance of LiVMoO6 cathode for lithium ion batteries, J Alloys Comp 457: 389-393.

11. Chen N, Wang C, Hu F, Bie X, Wei Y, et al. (2015) Brannerite-type vanadium-molybdenum oxide $\mathrm{LiVMoO}_{6}$ as a promising anode material for lithium-ion batteries with high capacity and rate capability. ACS Appl Mater Interfaces 7(29): 16117-16123.
12. Milanova M, Iordanova R, Tatsumisago M, Hayashi A, Tzvetkov P, et al (2016) Soft mechanochemical synthesis and electrochemical behavior of LiVMoO6 for all-solid-state lithium batteries, J Mater Sci 51: 35743584 .

13. Run R, Wadsley A (1966) The crystal structure of ThTi20 6 (brannerite). Acta Cryst 21: 974-978.

14. Baran EJ, Cabello CI, Nord AG (1987) Raman spectra of some MIIV206 brannerite- type metavanadates. J Raman Spectrosc 18: 405-407.

15. Tatsumisago M, Nagao M, Hayashi A (2013) Recent development of sulfide solid electrolytes and interfacial modification for all-solid-state rechargeable lithium batteries. J Asian Ceram Soc 1: 17-25.

16. Hayashi A, Sakuda A, Tatsumisago M (2016) Development of Sulfide Solid Electrolytes and Interface Formation Processes for Bulk-Type AllSolid-State Li and Na Batteries, Front. Energy Res 4: 25.

17. Cushing BL, Kang SH, Goodenough JB (2001) Instability of brannerite cathode materials upon lithium insertion. Int J Inorg Mater 3: 875-879.

\section{Your next submission with Juniper Publishers} will reach you the below assets

- Quality Editorial service

- Swift Peer Review

- Reprints availability

- E-prints Service

- Manuscript Podcast for convenient understanding

- Global attainment for your research

- Manuscript accessibility in different formats

( Pdf, E-pub, Full Text, Audio)

- Unceasing customer service

Track the below URL for one-step submission https://juniperpublishers.com/online-submission.php 